\title{
Evaluate the Inhibitory Ability of Fungicides and Biocontrol Agents against Pyricularia oryzae and Helminthosporium oryzae in vitro
}

\author{
Gaurav Kumar Yadav ${ }^{1}$, Ramesh Singh Yadav ${ }^{* *}$, Gopal Singh ${ }^{1}$, Kamal Khilari ${ }^{1}$, \\ Prashant Mishra ${ }^{1}$ and Hem Singh ${ }^{2}$ \\ ${ }^{1}$ Department of Plant Pathology, ${ }^{2}$ Department of Entomology, Sardar Vallabhbhai Patel \\ University of Agriculture \& Technology, Meerut-250110, (U.P.) India \\ *Corresponding author
}

\section{A B S T R A C T}

\begin{tabular}{l} 
K e y w o r d s \\
$\begin{array}{l}\text { Fungicides, } \\
\text { Concentration, } \\
\text { Bio-agents, } \\
\text { Basmati, Inhibition }\end{array}$ \\
Article Info \\
$\begin{array}{l}\text { Accepted: } \\
\text { 26 July 2020 } \\
\text { Available Online: } \\
\text { 10 August } 2020\end{array}$ \\
\hline
\end{tabular}

The study was carried out to evaluate the efficacy of fungicides and bio-agents against the blast and brown spot disease in basmati rice under in vitro condition. All three fungicides (Tricyclazole $75 \%$ WP, Propiconazole 25\% EC and hexaconazole 5\% EC) were found quite effective against the blast and brown spot disease of basmati rice. These fungicides were tested at three different concentrations i.e. $25 \mathrm{ppm}, 50 \mathrm{ppm}$ and $100 \mathrm{ppm}$. The bioagents (Trichoderma harzianum and Pseudomonas fluorescence) were less effective as compared to fungicides. Among the evaluated fungicides propiconazole shows maximum mycelium inhibition percent of $P$. oryzae both $25 \mathrm{ppm}$ and $50 \mathrm{ppm}$ concentration level that was $64.44 \%$ and $76.30 \%$ while at $100 \mathrm{ppm}$ concentration tricyclazole $(87.41 \%$ ) shows maximum inhibition percent. Hexaconazole was most superior and shows maximum mycelial growth inhibition of $H$. oryzae at all above three concentration of fungicide. Among the eco-friendly treatment $P$. fluorocens expressed better bio-agent against $P$. oryzae and $H$. oryzae as compared to $T$. harzianum.

\section{Introduction}

Rice (Oryza sativa L.) is the grain with second highest worldwide production after maize (Boumas, 1985). It belongs to the family Graminae. Rice is the predominant dietary energy source for 17 countries in Asia and the Pacific, 9 countries in North and South America and 8 countries in Africa. Rice is providing $20 \%$ of the world dietary energy supply, while wheat supplies $19 \%$ and maize $5 \%$. It is the staple food in developing countries. Rice is a high energy or high calorie food. In India, area under cultivation of non-Basmati rice is 431.94 lakh hectare with total output of 110.15 million tones with an average productivity of $2550 \mathrm{~kg} / \mathrm{ha}$ (Department of Agriculture and cooperation, Govt. of India, 2018).

Basmati rice holds a place of pride for India due to its aroma and cooking quality. This rice with extra-long, soft textured grain is being cultivated since time immemorial in the foot hills of Himalayas. India is the major producer and suppliers of basmati rice to the 
world consumers. The Basmati rice area across major Indian states (Jammu \& Kashmir, Himachal Pradesh, Punjab, Haryana, Delhi, Uttrakhand and Western Uttar Pradesh) is 1515.00 thousand ha with Production of 5027.00 thousand tones. The area and production of Basmati rice in Western Uttar Pradesh is 251.00 thousand ha and 730.00 thousand tones (APEDA, 2018) respectively. Basmati rice is known to be attacked by many pests and diseases which cause huge losses annually worldwide.

Among fungal diseases of rice, rice blast (Pyricularia oryzae) and brown spot (Helminthosporium oryzae) is of significant economic importance. Outbreaks of rice blast and brown spot diseases are a serious and recurrent problem in all rice growing regions of the world. It is estimated that each year enough of rice is destroyed by rice blast alone to feed 60 million people (Zeigler et al., 1994). Brown spot disease causes severe yield loss in 1942 in West Bengal popularly known as Bengal famine and yield loss reaches up to 90\% in certain areas (Sarkar et al., 2014).

Currently these diseases are being managed by application of chemical fungicides such as tricyclozole, propiconazole, hexaconazole, carbendazim, mancozeb, etc. and many workers have reported these chemicals are effective against rice blast (Hegde, 2015). Some workers were worked on the evaluation of organic or botanical product for management of rice blast and brown spot diseases. Management through fungicides is one of the most widely used management methods, but they are costly and at the same time the chemical have an adverse impact on environment. However, current research indicates another potential option for plant disease management through the use of biocontrol agents (Nirmalkar et al., 2017). The objectives of the study were to develop a cost effective protection measures for management of rice diseases for sustainable yield.

\section{Materials and Methods}

Experiment was conducted to evaluate different concentration of fungicides and isolated bio-control against Pyricularia oryzae and Helminthosporium oryzae in vitro. The experiment was conducted at Centre of Excellence for Sanitary and Phytosanitary (SPS), Department of Plant Pathology of Sardar Vallabhbhai Patel University of Agriculture and Technology Modipuram, Meerut, U.P.

\section{Isolation and purification of the pathogen}

Infected plant of basmati rice having the characteristics symptoms was collected for the isolation of pathogens. The infected plant parts were washed with sterilized water and cut into small sections containing both the disease and healthy looking tissue by sterilized scalpel. The sections were surface sterilized by dipping into $0.25 \%$ sodium hypochloride solution for $15-20$ seconds and washed by 5 changes of sterilized distilled water. Small sections of infected plant were then demoisturized by placing those folds of sterilized blotting paper and transferred aseptically to Petri dishes containing the water agar medium. The Petri dishes were incubated for $25^{\circ} \mathrm{C} \pm 1$ for 5-7 days for sparse growth and sporulation of each pathogens associated with the diseased tissue. In each Petri dish, 5 pieces of each infected tissues were inoculated. After incubation, the growths were observed under the microscope for production of spores of Pyricularia oryzae and Helminthosporium oryzae. After fragments of hyphal growth from the growing tips were transferred to fresh PDA slants. Pure culture was made, following repeated hyphal tip transfer. 
In vitro evaluation of efficacy of different fungicides

In vitro test of the fungicidal effect of various fungicides namely Tricyclazole, Propiconazole and Hexaconazole was evaluated at 25,50 , and $100 \mathrm{ppm}$ concentrations by food poison technique Control will be maintained without addition of fungicides. The test fungus was allowed to grow on PDA medium and the colony diameter was recorded on per cent inhibition basis over control. Each chemical was tested at three different concentrations. Requisite quantities of each fungicide were accurately added in to medium. The contents well stirred and mixed thoroughly and poured on to three petridishes (90 $\mathrm{mm}$ diameter). Seven days old culture grown on agar media is used as inoculum and was transferred aseptically in to the center of each petridish containing poisoned nutrient medium. The petridishes were kept in the incubator along with checks kept without toxicant. Each treatment was replicated thrice. The diameter of the radial growth of colonies in each of the treatments was measured in four directions lengthwise and breadth wise and mean was calculated. The observations were made and compared with the check and per cent inhibition of mycelial growth was determined using the formula given below.

\section{Dual culture technique}

A mycelial disc $(5 \mathrm{~mm}$.), obtained from the peripheral region of 5-7 day old culture of pathogens on PDA, was placed on fresh PDA plate $(3 \mathrm{~cm}$ from centre) then a $5 \mathrm{~mm}$ mycelial disc, obtained from the periphery of a 5-7 day old culture of fungal bio agents were placed $3 \mathrm{~cm}$ away from the inoculum of the pathogen, for bacterial bio agents were streaked $3 \mathrm{~cm}$ away from the inoculum of the pathogen. Three replication of each treatment were maintained with one control set without inoculating the bio inoculants. Then the plates were incubated at $26+1{ }^{0} \mathrm{C}$, the measurements were taken after 7 days. At the end of incubation period, radial growth of mycelium was measured. Radial growth reductions were calculated in relation to growth of the control as following:

$$
\mathrm{I}=\frac{C-T}{C} \times 100
$$

Where, I = Per cent inhibition of mycelium

$\mathrm{C}=$ Colony diameter $(\mathrm{mm})$ in control

$\mathrm{T}=$ Colony diameter $(\mathrm{mm})$ in treatment

\section{Results and Discussion}

The efficacy of fungicides against $P$. oryzae and $H$. oryzae at different concentrations is shown in Table 1 and 2 . The results of in vitro studies revealed that highly significant inhibition of mycelial growth was observed with the fungicides compared to control. It is also observed that in some of fungicides mycelial inhibition increased with corresponding increase in concentration of the chemicals.

The results from Table 1 indicated that, all three tested fungicides inhibited the growth of $P$. oryzae. Among them at $25 \mathrm{ppm}$ concentration maximum mycelial growth inhibition per cent of $P$. oryzae was recorded in proiconazole $(64.44 \%)$ after 144 hours, which is superior from all the tested fungicides followed by hexaconazole (64.74\%) and tricyclazole (22.59\%). Mycelial growth inhibition was recorded highest in propiconazole $(76.30 \%)$ followed by hexaconazole $(71.85 \%)$ and tricyclazole (62.96\%) at 50ppm concentration level. While at $100 \mathrm{ppm}$ concentration tricyclazole $(87.41 \%)$ shows maximum growth inhibition percent followed by propiconazole $(81.48 \%)$ and by hexaconazole (80.74\%). Nirmalkar $e t$ al., (2017) evaluated different fungicides and reported that tricyclazole 75\% WP was 
effectively managed the incidence blast and reduced the incidence up to $78.13 \%$.

The Table 2 reveals that, inhibition of mycelial growth of $H$. oryzae varied significantly with different concentration of fungicides. Among them at 25ppm concentration maximum mycelial growth inhibition per cent of $H$. oryzae was recorded in hexaconazole $(28.15 \%)$ after 144 hours, which is superior from all the tested fungicides followed by tricyclazole $(27.04 \%)$ and then proiconazole (13.70\%). Mycelial growth inhibition was recorded highest in hexaconazole $(48.52 \%)$ followed by tricyclazole $(42.96 \%)$ and after that propiconazole $(16.67 \%)$ at $50 \mathrm{ppm}$ concentration level. While at 100ppm concentration again hexaconazole $(57.04 \%)$ shows maximum growth inhibition percent followed by tricyclazole $(44.81 \%)$ and after that propiconazole $(23.70 \%)$. Nayak et al., (2019) also observed that, the maximum mean per cent of mycelial inhibition was in propiconzole $25 \%$ EC (100\%) (Fig. 1-4).

Table.1 Efficacy of different fungicides against $P$. oryzae

\begin{tabular}{|c|c|c|c|c|}
\hline S. No. & Name of Fungicide & Concentration & Redial growth (mm) & Percent inhibition \\
\hline \multirow[t]{3}{*}{1.} & \multirow[t]{3}{*}{ Tricyclazole } & $25 \mathrm{ppm}$ & 69.70 & 22.59 \\
\hline & & 50ppm & 33.33 & 62.96 \\
\hline & & 100ppm & 11.30 & 87.41 \\
\hline \multirow[t]{3}{*}{2.} & \multirow[t]{3}{*}{ Propiconazole } & $25 \mathrm{ppm}$ & 32.00 & 64.44 \\
\hline & & 50ppm & 21.30 & 76.30 \\
\hline & & 100ppm & 17.00 & 81.48 \\
\hline \multirow[t]{5}{*}{3.} & \multirow[t]{3}{*}{ Hexaconazole } & $25 \mathrm{ppm}$ & 35.30 & 60.74 \\
\hline & & 50ppm & 25.30 & 71.85 \\
\hline & & 100ppm & 17.00 & 80.74 \\
\hline & Control & - & 90.00 & - \\
\hline & CD & - & 2.80 & - \\
\hline
\end{tabular}

Table.2 Efficacy of different fungicides against $H$. oryzae

\begin{tabular}{|l|l|c|c|c|}
\hline S. No. & Name of Fungicide & Concentration & Redial growth (mm) & Percent inhibition \\
\hline $\mathbf{1}$ & Tricyclazole & $25 \mathrm{ppm}$ & 65.70 & 27.04 \\
\cline { 3 - 5 } & & $50 \mathrm{ppm}$ & 51.33 & 42.96 \\
\cline { 3 - 5 } & & $100 \mathrm{ppm}$ & 49.67 & 44.81 \\
\hline $\mathbf{2}$ & \multirow{2}{*}{ Propiconazole } & $25 \mathrm{ppm}$ & 77.67 & 13.70 \\
\hline & & $50 \mathrm{ppm}$ & 75.00 & 16.67 \\
\hline \multirow{2}{*}{$\mathbf{3}$} & \multirow{2}{*}{ Hexaconazole } & $100 \mathrm{ppm}$ & 68.67 & 23.70 \\
\hline \multirow{2}{*}{} & & $25 \mathrm{ppm}$ & 64.67 & 28.15 \\
\hline & & $50 \mathrm{ppm}$ & 46.33 & 48.52 \\
\hline & & $100 \mathrm{ppm}$ & 38.67 & 57.04 \\
\hline & Control & - & 90 & - \\
\hline & CD & - & 3.53 & - \\
\hline
\end{tabular}


Table.3 Efficacy of different bio agents against $P$. oryzae

\begin{tabular}{|c|c|c|c|}
\hline S. No. & Name of bio agents & Radial growth & Per cent control \\
\hline 1. & Trichoderma harzianum & 41.00 & 54.44 \\
\hline 2. & Pseudomonas fluorescence & 37.67 & 58.15 \\
\hline & Control & 90.00 & - \\
\hline & CD & 1.90 & - \\
\hline
\end{tabular}

Table.4 Efficacy of different bio agents against $H$. oryzae

\begin{tabular}{|c|c|c|c|}
\hline S. No. & Name of bio agents & Radial growth & Per cent control \\
\hline $\mathbf{1 .}$ & Trichoderma harzianum & 42.33 & 52.96 \\
\hline $\mathbf{2 .}$ & Pseudomonas fluorescence & 37.33 & 58.52 \\
\hline & Control & 90.00 & - \\
\hline & CD & 2.12 & - \\
\hline
\end{tabular}

Fig.1 Efficacy of different fungicides on P. oryzae

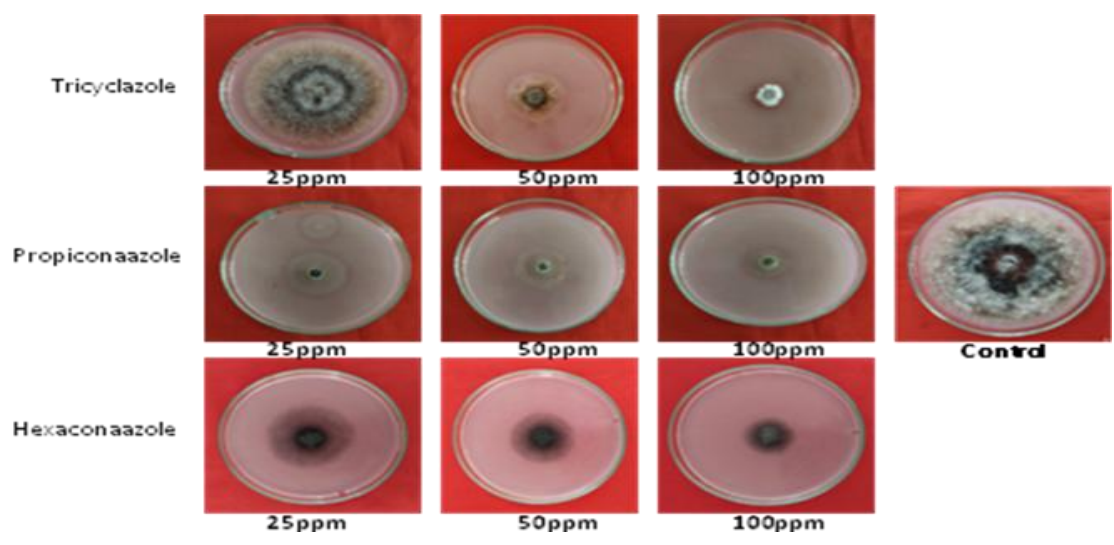

Fig.2 Efficacy of different fungicides on $H$. oryzae

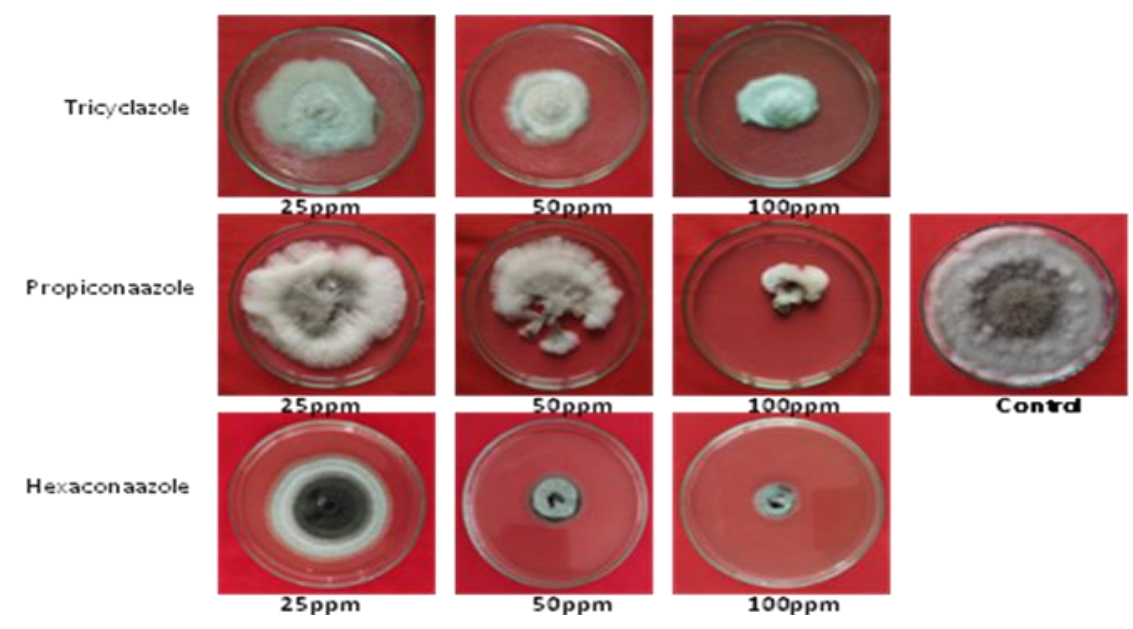


Fig.3 Efficacy of different bio agents against $P$. oryzae
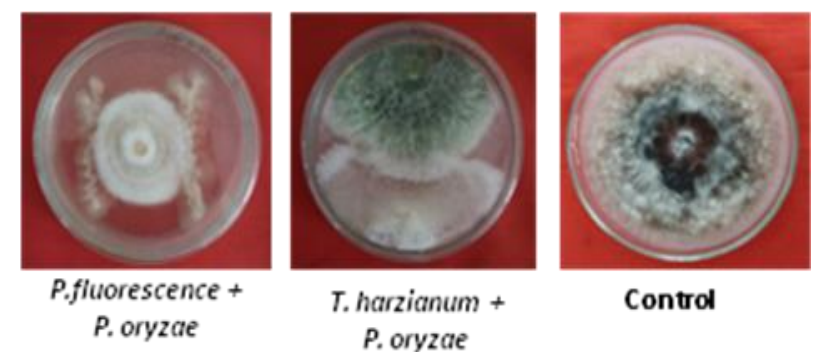

Control

Fig.4 Efficacy of different bio agents against $H$. oryzae

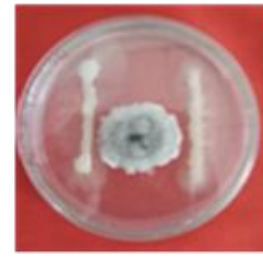

P.fluorescence + H. oryzae

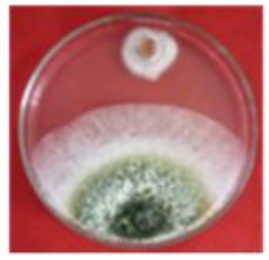

T. harzianum + P. oryzae

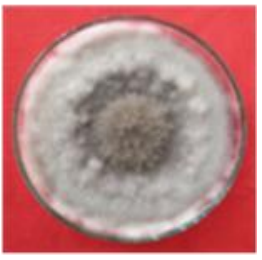

Control
The results from the Table 3 indicated that, all tested bioagents inhibited the growth of $P$. oryzae. Among the maximum inhibition per cent $(58.15 \%)$ was recorded with Pseudomonas fluorescence Pf008 Trichoderma spp. after 144 hours, which is superior from Trichoderma harzianum isolate TS009 which shows (54.44\%) mycelial growth inhibition. Nirmalkar et al., (2017) showed that in eco-friendly treatment $P$. fluorescens expressed better results against blast.

Table 4 shows that, all tested bioagents inhibited the growth of $P$. oryzae. Among the maximum inhibition per cent $(58.52 \%)$ was recorded with Pseudomonas fluorescence Pf008 Trichoderma spp. after 144 hours, which is superior from Trichoderma harzianum isolate TS009 which shows (52.96\%) mycelial growth inhibition. Nayak et al., (2019) also found that Pseudomonas fluorescens shows maximum mycelial inhibition $(62.75 \%)$ followed by Bacillus subtilis $(51.76 \%)$. Least percent mycelial inhibition was observed with fungal antagonistic organism harzianum $(27.06 \%)$.

\section{References}

APEDA, 2018. Basmati Survey Report -6, http://apeda.gov.in/ apedawebsite/ Announcements/Basmati_Crop_surve y_Report_6_Season_2018.pdf.

Bhat, Z.A., Bhat, G.N., Ahanger, M.A., Rather, A.G., Bhat, M.A, Najeeb, S., Sheikh, F.A. and Sanghera, G. S. 2012. Bioefficacy of fungitoxicants against blast disease (Pyricularia grisea) in rice under temperate conditions of Kashmir, India. Global Journal of Applied Agricultural Research. 2 (1): pp. 11-14.

Boumas, G. 1985. Rice grain handling and storage. Elsevier Science Publishers. B.V.9-10.

Deepan, A.B., Tanuja, N., Kavanashree, K.S. and Ramanathan, A. (2017). Screening and management of false smut disease in rice-A review, Agricultural Reviews, 38(3): 238-242. 
Department of Agriculture and cooperation, Govt. of India, 2018. Production crop2018 data, Food and agriculture of the united nation, Department of Agriculture and cooperation, Govt. of India (2018).

Gupta, V., Shamas, N., Razdan, V. K., Sharma, B. C., Sharma R., Kaur, K., Singh, I., John, J. and Kumar, A. 2013. Foliar application of fungicides for the management of brown spot disease in rice (Oryza sativa L.) caused by Bipolaris oryzae. African Journal Agricultual Research. 8(25): 33033309

Hegde, G.M. 2015. Efficacy of tebuconazole $25 \% \mathrm{WG}$ against blast and sheath blight diseases of rice in central western ghats of uttar kannada district. The Bioscan (Supplement on Plant Pathology) 10(4): 1771-1775.

Kumar, H., Ahmad, S. And Zacharia, S. 2015. Efficacy of fungal, bacterial bioagents and botanicals against brown spot (Helminthosporium oryzae) of rice (Oryzae sativa). Research Journal of Chemical and Environmental Sciences. 3(2): 27-31.

Nayak, M.S. and Hiremath, S.V. 2019. In vitro efficacy of fungicides, botanicals and bioagents against brown leaf spot of rice caused by bipolaris oryzae. International Journal Pure and Applied Bioscience. 7(2): 375- 781.

Neelakanth, Gowda, D.K., Chethana, B.S. and Parasappa, H.H. 2017. In vitro and in vivo evaluation of fungicides against Pyricularia oryzae causing blast of rice. International Journal Pure and Applied Bioscience. 5(3): 259-263.

Nirmalkar, V. K., Said, P. P. and Kaushik, D.K. 2017. Efficacy of fungicides and bio-agents against Pyricularia gresia in paddy and yield gap analysis thought frontline demonstration. International Journal of Current Microbiology and Applied Sciences.6(4): 2338-2346.

Sarkar, D., Mandal, R., Roy, P., Taradar, J. and Dasgupta, B. 2014. Management of brown spot disease of rice by using safer fungicides and some bioagents. The Bioscan, (Supplement on Plant Pathology).9(1): 437-441.

Zeigler, R.S., Leong, S.A. and Teng, P. 1994. Rice blast disease: International Rice Research Institute, Manila, Philippines.

\section{How to cite this article:}

Gaurav Kumar Yadav, Ramesh Singh Yadav, Gopal Singh, Kamal Khilari, Prashant Mishra and Hem Singh. 2020. Evaluate the Inhibitory Ability of Fungicides and Biocontrol Agents against Pyricularia oryzae and Helminthosporium oryzae in vitro. Int.J.Curr.Microbiol.App.Sci. 9(08): 3569-3575. doi: https://doi.org/10.20546/ijcmas.2020.908.411 